\title{
Synthesis and study of polyfunctional silicon-containing amines as adhesion promoters of epoxyamine compounds
}

\author{
(C) Christina Y. Ivanova, Mikhail V. Kuzmin,* \\ Oleg A. Kolyamshin, and Nikolay I. Koltsov ${ }^{+}$ \\ Department of Physical Chemistry and High Molecular Compounds. Chuvash State University \\ named after I.N. Ulyanov. Moskovsky Ave., 15. Cheboksary, 428015. Chuvash Republic. Russia. \\ Phone:+7 (8352)45-24-68.E-mail: koltsovni@mail.ru
}

*Supervising author; ${ }^{+}$Corresponding author

Keywords: aminoalkoxysiloxanes, adhesion promoters, epoxyamione compounds.

\begin{abstract}
At present, in order to obtain high-tech hybrid products, high demands are placed on modern adhesives for creating durable joints between dissimilar materials. It is known that adhesion depends on the compatibility of the adhesives with the surfaces of the materials. For epoxy compositions, amine compounds are the main hardeners. In this regard, in the presented work, silicon-containing amines were synthesized based on polyfunctional aminoalkoxysiloxanes for epoxy compositions, the strength of attachment of which to various metal substrates was studied using these adhesion promoters. Aminoalkoxysiloxanes were prepared by reacting 3-aminopropyltriethoxysilane with monoethanolamine in nitrogen at atmospheric pressure in the presence of a binary antioxidant and catalytic amounts of an alkali metal alcoholate. To carry out the reaction in a homogeneous phase, the reaction mixture was heated to a temperature of $100-110^{\circ} \mathrm{C}$ and distilled off to $90 \%$ of ethanol from the theoretically calculated amount. Further, the reaction was carried out at a reduced temperature of 10-20 millimeter of mercury pressure until the release of alcohol stops. At the same time, gravimetric control was carried out and the refractive index of the reaction mixture was measured. As a result, aminoalkoxysilanes were obtained in the form of light-yellow oily liquids. The structure of the obtained compounds was investigated by IR-spectroscopy on a Fourier spectrophotometer FSM-1202 and ${ }^{1} \mathrm{H}$ NMRspectroscopy on a high-resolution BrukerWM-250 NMR-spectrometer. It was found that under the selected synthesis conditions, aminopropyl-tri-(2-aminoethoxy)silane is obtained with the highest yield of $97.6 \%$ at a molar ratio of 3-aminopropyltriethoxysilane (AGM-9) with monoethanolamine 1: 3 . The obtained compounds were used in the composition of epoxy compounds in order to improve their physical and mechanical properties. The adhesion properties of epoxy compositions based on ED-22 epoxy resin and isophorone diamine were studied using synthesized polyfunctional aminoalkoxysiloxanes as adhesion promoters. It was found that the most effective adhesion promoter is aminopropyl-tri-(2-aminoethoxy) silane.
\end{abstract}

\section{References}

[1] L.G. Rogozhina, M.V. Kuz'min, V.A. Ignat'ev, O.A. Kolyamshin, N.I. Kol'tsov. Effect of alkanolamines on properties of epoxy-anhydride compounds. Russian Journal of Applied Chemistry. 2016. Vol.89. P.1846-1852. doi:10.1134/S1070427216110161

[2] A.I. Zagidullin, M.V. Kolpakova, R.M. Garipov, O.V. Stoyanov. Structure and properties of epoxy composites hardened with new silicon-containing amines. Adhesives. Sealants. Technology. 2008. №1. P.17-19. doi: 10.1134/S1995421208030052

[3] Sukanya Pradhan, Smita Mohanty, Sanjay K. Nayak. Waterborne epoxy adhesive derived from epoxidized soybean oil and dextrin: Synthesis and characterization. Intern. J. of Polymer Analysis and Characterization. 2017. Vol.22. No.4. P.318-329.

[4] K.A. Medvedeva, D.G. Miloslavsky, E.N. Cherezova, and E.M. Gotlib. Studying the process of foaming of epoxy resin in the presence of new polyaminoalkylphenols acting as a blowing agent and hardener Butlerov Communications. 2015. Vol.41. No.1. P.96-100. DOI: 10.37952/ROI-jbc-01/15-41-1-96

[5] R. Rajan, E. Rainosalo, S.P. Thomas, S.K. Ramamoorthy, J. Zavašnik, J. Vuorinen, M. Skrifvars. Modification of epoxy resin by silane-coupling agent to improve tensile properties of viscose fabric composites. Polymer Bulletin. 2018. Vol.75. No.1. P.167-195. https://doi.org/10.1007/s00289-017-2022-2

[6] L.A. Brusnitsina, T.A. Alekseeva, and E.I. Stepanovskih. Modeling of swelling of epoxy-rubber adhesive layer 

in organic solvents. Butlerov Communications. 2015. Vol.44. No.12. P.48-53. DOI: 10.37952/ROI-jbc-01/1544-12-48

[7] K. Mishra, L.K. Babu. Influence of Naturally Occurring Fiber (Switchgrass) Reinforcement on the Mechanical Properties of Epoxy Resin. Biomed J. Sci. \& Tech. Res. 2019. Vol.20. No.2. P.14861-14863. DOI: 10.26717/BJSTR.2019.20.003418

[8] E.N. Mochalova, I.V. Lounev, M.F. Galikhanov, I.A. Gabrakhmanov, R.R. Fatikhova, Yu.A. Gusev, and R.Ya. Deberdeev. Study of electret and dielectric properties of epoxiamine polymer materials. Butlerov Communications. 2017. Vol.49. No.1. P.91-97. DOI: 10.37952/ROI-jbc-01/17-49-1-91

[9] A.A. Efremov, A.I. Zagidullin, M.V. Kolpakova et al. Use of organosilicon compounds as modifiers of epoxy compositions. Polym. Sci. Ser. D. 2008. No.1. P.244-248. DOI: 10.1134/S19954 21208040060

[10] Hua Yao, Jianzhong Hang, Xiaoying Sun, Lujiang Jin, Liyi Shi \& Jing Zhang. Preparation and anticorrosive behavior of epoxy-polysiloxane hybrid coatings modified by polyetheramines. Journal of Adhesion Science and Technology. 2014. Vol.28. No.12. P.1103-1116. DOI: 10.1080/016942 43.2013.875609 